\title{
Gambaran Pengetahuan, Sikap dan Tindakan Mahasiswa Fakultas Ekonomi Universitas Andalas Angkatan 2013 tentang Stroke
}

\author{
Karina Prasasti Helhid ${ }^{1}$, Yuliarni Syafrita ${ }^{2}$, Ennesta Asri $^{3}$
}

\begin{abstract}
Abstrak
Stroke merupakan penyebab utama kecacatan pada kelompok usia diatas 45 tahun dan penyebab nomor dua kematian secara global. Stroke dapat dicegah, salah satunya dengan memberikan pengetahuan kepada mahasiswa sebagai generasi muda. Tujuan penelitian ini adalah untuk mengetahui gambaran pengetahuan, sikap dan tindakan mahasiswa Fakultas Ekonomi Universitas Andalas angkatan 2013 tentang stroke. Jenis penelitian ini adalah deskriptif dengan desain cross sectional. Teknik pengambilan sampel adalah consecutive sampling dengan jumlah sampel 85 orang. Penelitian ini dilakukan bulan Januari 2016 sampai Juni 2016. Pengumpulan data dilakukan melalui kuesioner dengan menggunakan analisis manual. Hasil penelitian didapatkan gambaran pengetahuan responden pada kategori baik sebanyak $47,1 \%$ dan kategori sedang sebanyak 52,9\%. Gambaran sikap responden kategori baik sebanyak $77,6 \%$ dan kategori sedang 22,4\%. Gambaran tindakan responden pada kategori baik sebanyak $75,3 \%$ dan kategori sedang $24,7 \%$. Simpulan penelitian ini adalah didapatkan pengetahuan pada kategori sedang terdapat pada lebih dari separuh responden, sikap dan tindakan sebagian besar responden pada kategori baik.
\end{abstract}

Kata kunci: stroke, pengetahuan, sikap, tindakan

\section{Abstract}

Stroke is the main cause of disability for peoples above 45 years old. It can be prevented by giving education to students. The objective of this study was to identify the level of knowledge, attitude and action of the students in Economy Faculty of Andalas University badge of 2013 about stroke. This research based on descriptive study with cross sectional method. The consecutive sampling was used to obtain 85 students. This research had done from January 2016 until June 2016. Data was collected by questionnaire by using manual analysis. The result of the research was obtained that for the knowledge represent in good category is $47.1 \%$ and in middle category is $52.9 \%$. Attitude represent in good category was $77.6 \%$ and middle category is $22.4 \%$. The action represent in good category is $\mathbf{7 5 . 3} \%$ and middle category is $\mathbf{2 4 . 7 \%}$. The conclution of this study is category for the knowledge more than a half represent is the middle, category of attitude and action the most represent are good.

Keywords: stroke, knowledge, attitude, action

Affiliasi penulis: 1. Prodi Pendidikan Dokter Fakultas Kedokteran Universitas Andalas Padang (FK Unand), 2. Bagian Neurologi FK Unand/RSUP Dr. M Djamil Padang , 3. Bagian Dermatologi dan Venerologi FK Unand/RSUD Dr. M Djamil Padang.

Korespondensi: Karina Prasasti Helhid,

Email: karinaprasastihelhid@yahoo.co.id

\section{PENDAHULUAN}

Stroke merupakan salah satu penyebab utama kecacatan pada kelompok usia diatas 45 tahun. Penyakit ini sering menimbulkan permasalahan yang komplek, baik dari segi kesehatan, ekonomi, maupun sosial. ${ }^{1}$ Penderita stroke akan dapat mengalami 
keterbatasan fungsi organ (impairment) sehingga menyebabkan ketidakmampuan (disability) berjalan, berpakaian, berkomunikasi dan lain-lain. Kondisi ini menyebabkan keterbatasan peran sosial pada penderita stroke, yaitu; terganggunya kemampuan aktualisasi diri untuk berperan secara sosial, budaya, dan ekonomi dalam keluarga, seperti tidak dapat berperan sebagai ayah atau tidak dapat bekerja untuk memenuhi kebutuhan keluarga. ${ }^{2}$

Seseorang dapat menderita stroke apabila terpapar faktor risiko. ${ }^{3}$ Faktor risiko yang berhubungan dengan kejadian stroke dibagi menjadi 2 kelompok, yaitu yang tidak dapat dimodifikasi dan yang dapat dimodifikasi. Faktor risiko yang tidak dapat dimodifikasi meliputi usia, jenis kelamin, riwayat stroke dalam keluarga dan riwayat stroke. ${ }^{4}$ Beberapa faktor risiko stroke yang dapat dimodifikasi yaitu hipertensi (25-40\%), kurang aktivitas fisik (25\%), obesitas (25\%), diabetes melitus, dislipidemia, riwayat penyakit jantung dan merokok. ${ }^{5}$

Pengendalian faktor risiko yang dapat dimodifikasi tersebut diharapkan dapat menurunkan insiden dan prevalensi stroke. Pengetahuan masyarakat dalam mengetahui faktor risiko, gejala klinis dan pengetahuan lain tentang stroke sangat penting untuk mewujudkan tujuan tersebut agar dapat segera diberi pengobatan. ${ }^{6}$

Saat ini belum ada pengobatan yang efektif dan efisien untuk stroke karena sifatnya yang multikausal (disebabkan banyak faktor). Upaya pencegahan merupakan salah satu cara yang paling efektif dan efisien untuk mengurangi angka kejadian stroke. Upaya pencegahan baru dapat dilakukan jika mengetahui faktor risiko apa saja yang dapat menyebabkan serangan stroke.Pengetahuan terhadap faktor risiko stroke sangat diperlukan untuk merumuskan cara pencegahan yang efektif. ${ }^{7}$

Pengetahuan merupakan hasil dari tahu yang terjadi setelah seseorang melakukan pengindraan terhadap suatu objek tertentu. Pengindraan terjadi melalui pancaindra manusia yaitu; indra penglihatan, pendengaran, perciuman, rasa dan raba. Sebagian besar pengetahuan manusia diperoleh melalui mata dan telinga. Pengetahuan yang mencakup dalam domain kognitif mempunyai 6 tingkatan, yaitu; tahu (know), memahami (comprehension), aplikasi (application), analisis (analysis), sintesis (synthesis) dan evaluasi (evaluation). ${ }^{8}$

Sikap merupakan reaksi atau respon yang masih tertutup dari seseorang terhadap suatu stimulus atau objek. ${ }^{11}$ Komponen sikap adalah kognitif, afektif dan konatif. Tingkatan sikap yaitu menerima (receiving), merespon (responding), menghargai (valuting) dan bertanggung jawab (responsible). ${ }^{9}$

Tindakan merupakan mekanisme dari suatu pengamatan yang muncul dari persepsi sehingga ada respon untuk melakukan sesuatu. Tindakan juga mempunyai beberapa tingkatan, yaitu; persepsi (perception), respon terpimpin (guide response), mekanisme (mechanism) dan adaptasi. ${ }^{10}$

Fakultas Ekonomi merupakan salah satu fakultas di Universitas Andalas yang tidak mendapatkan perkuliahan tentang stroke sehingga dapat diasumsikan sebagai pendapat masyarakat umum. Fakultas ekonomi memiliki jumlah mahasiswa terbanyak di Universitas Andalas sehingga diharapkan penelitian ini dapat menyerupai keadaan sesungguhnya dan berguna pada keadaaan yang serupa.

Berdasarkan uraian di atas, penulis tertarik untuk melakukan penelitian tentang gambaran pengetahuan, sikap, dan tindakan mahasiswa fakultas ekonomi universitas andalas angkatan 2013 tentang stroke.

\section{METODE}

Penelitian ini berjenis deskriptif, dengan desain penelitian cross-sectional. Penelitian ini dilakukan di Fakultas Ekonomi Universitas Andalas, pada bulan Januari sampai bulan Juni 2016. Pengambilan sampel menggunakan teknik simple random sampling sehingga jumlah sampel 85 orang. 
HASIL

\section{Karakteristik Subjek}

Tabel 1. Distribusi berdasarkan karakteristik responden

\begin{tabular}{clcc}
\hline No & \multicolumn{1}{c}{ Karakteristik } & $(\mathbf{n}=\mathbf{8 5})$ & $\mathbf{( \% )}$ \\
\hline 1. & Jenis kelamin: & & \\
& laki-laki & 30 & 35,3 \\
& perempuan & 55 & 64,7 \\
2. & Usia : & & \\
& 19 tahun & 2 & 2,4 \\
& 20 tahun & 33 & 38,8 \\
& 21 tahun & 43 & 50,5 \\
& 22 tahun & 6 & 7,1 \\
& 23 tahun & 1 & 1,2 \\
\hline
\end{tabular}

Berdasarkan Tabel 1 didapatkan bahwa sebagian besar responden adalah perempuan $(64,7 \%)$ dan berusia $20-21$ tahun $(89,3 \%)$.

\section{Gambaran Data Variabel Pengetahuan}

Tabel 2. Distribusi variabel responden berdasarkan pengetahuan

\begin{tabular}{ccc}
\hline Pengetahuan & $(\mathbf{n}=\mathbf{8 5})$ & $\mathbf{( \% )}$ \\
\hline Baik & 40 & 47,1 \\
Sedang & 45 & 52,9 \\
Kurang & 0 & 0,0 \\
\hline
\end{tabular}

Berdasarkan Tabel 2 didapatkan tingkat pengetahuan dengan kategori sedang memiliki persentase paling besar yaitu $52,9 \%$.

\section{Gambaran Data Variabel Sikap}

Tabel 3. Distribusi variabel frekuensi responden berdasarkan sikap

\begin{tabular}{ccc}
\hline Sikap & $(\mathbf{n = 8 5 )}$ & $\mathbf{( \% )}$ \\
\hline Baik & 66 & 77,6 \\
Sedang & 19 & 22,4 \\
Kurang & 0 & 0,0 \\
\hline
\end{tabular}

Berdasarkan Tabel 3 dapat dilihat bahwa tingkat sikap dengan kategori baik yaitu $77,6 \%$.

\section{Gambaran Data Variabel Tindakan}

Tabel 4. Distribusi variabel frekuensi responden berdasarkan tindakan

\begin{tabular}{ccc}
\hline Tindakan & $(\mathbf{n}=\mathbf{8 5})$ & $\mathbf{( \% )}$ \\
\hline Baik & 64 & 75,3 \\
Sedang & 21 & 24,7 \\
Kurang & 0 & 0,0 \\
\hline
\end{tabular}

Berdasarkan Tabel 4 didapatkan bahwa bahwa tingkat sikap dengan kategori baik memiliki persentase paling besar yaitu $75,3 \%$.

\section{PEMBAHASAN}

Berdasarkan hasil penelitian yang dilakukan pada mahasiswa Fakultas Ekonomi Universitas Andalas Angkatan 2013 didapatkan bahwa tingkat pengetahuan berada pada kategori sedang (52,9\%), sikap berada pada kategori baik $(77,6 \%)$, dan tindakan berada pada kategori baik $(75,3 \%)$.

\section{Pengetahuan}

Hasil penelitian ini menunjukkan bahwa pengetahuan responden berada pada kategori sedang (52,9\%). Penelitian ini setara dengan penelitian yang dilakukan oleh Lee (2011) pada mahasiswa di Universitas Sumatera Utara yang mendapatkan kategori baik $(58,7 \%)$ mengenai pengetahuan tentang stroke. ${ }^{11}$

Tingkat pengetahuan yang relatif kurang pada responden dari penelitian ini berbeda dengan hasil penelitian sebelumnya, ini dapat dipengaruhi oleh beberapa hal seperti kurangnya perhatian responden tentang stroke atau responden kurang menerima informasi-informasi dari media massa, petugas kesehatan, orang tua, dan dokter keluarga tentang kejadian stroke, penyebab, faktor risiko, dan gejala klinis tentang stroke sehingga memiliki pemahaman tentang stroke dengan kategori sedang. 


\section{Sikap}

Berdasarkan hasil penelitian disimpulkan bahwa sikap responden tentang stroke termasuk kategori baik yaitu sebanyak 66 responden $(77,6 \%)$. Hasil ini sejalan dengan hasil penelitian Lee (2011) yakni 64 responden memiliki kategori baik $(70,7 \%){ }^{11}$ Menurut penelitian yang dilakukan oleh Haghighi et al didapatkan hasil yang berbeda dengan hasil penelitian ini yaitu didapatkan sikap dengan kategori sedang sebanyak $78,7 \%$ responden. $^{6}$

Penelitian ini mengukur sikap responden dari segi gejala, faktor risiko, dan pencegahan stroke. Sikap responden yang dikategorikan baik ini dapat dipengaruhi oleh kebiasaan hidup, budaya, dan lingkungan disekitar responden yang mementingkan kesehatan.

\section{Tindakan}

Berdasarkan hasil penelitian didapatkan bahwa tingkat tindakan kategori baik memiliki persentase tertinggi yakni 64 responden $(75,3 \%)$. Hasil ini sama dengan hasil penelitian yang dilakukan oleh Lee (2011) mendapatkan $72,8 \%$ dikategorikan memiliki tindakan yang baik. ${ }^{11}$

Tindakan responden pada penelitian ini diukur dari segi pencegahan, gejala, dan faktor risiko stroke. Tindakan responden dikategorikan baik ini dapat dipengaruhi oleh informasi yang didapatkan dari media masa dan lingkungan yang berhubungan dengan tindakan stroke.

\section{SIMPULAN}

Didapatkan pengetahuan pada kategori sedang terdapat pada lebih dari separuh responden, sikap dan tindakan sebagian besar responden pada kategori baik.

\section{DAFTAR PUSTAKA}

1. Mulyatsih E. Stroke, petunjuk praktis bagi pengasuh dan keluarga klien pasca stroke. Jakarta: Badan Penerbit FKUI; 2010.

2. Wirawan RP. Rehabilitasi stroke pada pelayanan kesehatan primer. Maj Kedokt Indon. 2009;59(2): 63-4.

3. National Stroke Association (NSA). Stroke Risk factor. Australia: NSA; 2014.

4. National Stroke Assosiation (NSA). Public stroke prevention guidelines (diunduh 26 Januari 2016). Tersedia dari: http:/www.stroge.org/site/Page Server?pagename=RISK .

5. Goldszmidt AJ, Caplan LR. Esensial stroke. Jakata: EGC; 2009.hlm.52.

6. Haghighi AB, Karimi AA, Ghaffarpasand F. Knowledge attitude toward stroke risk factors, warning symptoms and treatment in an Iranian population (diunduh 10 Februari 2016). Tersedia dari: http;/wwwbiomedcentral.com/1471-2318/9/35.

7. Nastiti D. Gambaran faktor risiko kejadian stroke pada pasien stroke rawat inap di rumah sakit Krakatau Medika tahun 2011 (skripsi). Jakarta: Universitas Indonesia; 2012.

8. Notoadmodjo, S. Ilmu perilaku Kesehehatan. Jakarta: Rineka Cipta; 2003.

9. Azwar, S. Sikap manusia, teori dan pengukurannya. Yogyakarta: Pustaka Pelajar; 2009.

10. Notoadmodjo S. Metodologi penelitian kesehatan. Jakarta: Rineka Cipta; 2010.

11. Lee CM. Gambaran pengetahuan, sikap, dan tindakan mahasiswa fakultas ekonomi Universitas Sumatera Utara angkatan 2008 tentang stroke (skripsi). Medan: Fakultas Kedokteran Universitas Sumatera Utara; 2011. 